\title{
Conservation of Millet genetic Diversity in Eastern ghat High lands of Odisha
}

\author{
Biswa Sankar Das* \\ Programme Officer, Odisha Millet Mission, Watershed Support Service \& Activities Network, India
}

*Corresponding author: Biswa Sankar Das, Programme Officer, Odisha Millet Mission, Watershed Support Service \& Activities Network, India

\begin{abstract}
A total of 111no.of Germplasm of Millets with code no's have been assembled through formal process of Collaborative programme experimented from 2017 -2020 Cropping season. The Germplasm has been evaluated for various Agronomic traits (biotic, abiotic, grain quality, etc.). The organisation, Watershed Support service \& Activities Network (Wassan) with Odisha Millet Mission Project holds 111no.of Millet Germplasm collection with 108 no. of indigenous and 3 no. of rare types having information on important trait specific characters from the communities, community managed seed bank. The Present Paper highlights the assessment of Millet diversity assembled and conserved under Odisha Millet Mission Project \& thrust areas identified for future conservation and utilization.
\end{abstract}

Keywords: Collection \& Conservation; Evaluation: Future thrust; Introduction; Millets; Community seed bank: Trait specific Germplasm

\section{Introduction}

Millets having traits such as rich in fiber content, non -starch polysaccharides with some unique nutrients have attained recognition of "Nutri grains" having unique proteins and amino acids. Millets are grown in such a landscape of unfertile soil with acidic in nature and rich in iron, aluminium oxides by nature, less water holding capacity. Millets grow well in arid and semi - arid environments, requiring less water than other cereal crops. short duration condition ,high adaptability to droughts ,hardiness and delayed monsoon conditions with poor soil nutrients have allowed / widened the scope of their cultivation in semi -arid region under marginal farming communities In India the millet crop ecosystem has a rich diversity particularly in Minor millets (Finger millet, Foxtail millet, Kodo millet, Barnyard millet, Little millet, Pearl millet) grown from temperate to peninsular India. The major millets namely Sorghum and Pearl millet are widely cultivated in different parts of the country and in same tribal dominant districts of Odisha like Koraput, Rayagada, Gajapati .Six other millets are grouped under minor millets or small millets are Finger Millet (Eleusine coracana-L ), Little Millet ( Panicum sumantrans-Roth.ex Roem \& Schultz) , Foxtail Millet ( Setaria italica-L), Kodo Millet ( Paspalum scrobiculatum -L), has domesticated and widely cultivated in tribal districts of Odisha[1-5].
Sorghum biocolar -L (Sorghum) has been domesticated in Africa and widely cultivated in parts of India with also some parts of Odisha like hilly tracts of Koraput, Rayagada, Gajapati, and Kandhamal. Pearl Millet has been domesticated in West Africa and widely cultivated some tribal parts of Odisha.

As Per the Minor Millets or Small Millets are Consider in the biggest area under cultivation is Finger Millet (Eleusine coracanaL) is widely distributed in all high Uplands of Semi -Arid zones in tribal areas of Odisha, which is originated from Africa \& now domesticated with exhibits good variability in Primitive landraces.

There is an incessant demand for these crops with desired \& important traits to meet the farmers need to better production as well as consumers need to global food security and increased resilient to climate change, for which a broader spectrum of Genetic Diversity with biotic and abiotic traits are required .In view of shrinking areas under cultivation in millets and millets fall under the priority groups for conservation for wider use in crop improvement programmes, there is need to augment and conserve the Genetic Diversity to capture the wider range of alleles .

In the recent decades, there has been loss of the Genetic diversity of many more crops .many crops have become susceptible 
to disease, pest and environmental stress .the concept of Gene bank which stores the Germplasm of the major crops such as Cereals ,legumes ,tubers ,etc .While the minor Crops remains Neglected cultivars, local landraces, wild species of these crops need to be conserved that might otherwise become extinct.

In this Paper the efforts to words networking approach for Conservation, future planning \& execution PGR management (Participatory grantee) of millets has been discussed.

\section{Materials \& Methods}

Information / Passport information available after Focus group discussion (FGD), interaction with farmers ,farming communities about diversity of millets ,Present available of landraces ,special characters or landraces information's are collected with some quantity of millet seeds collected to the meet the purpose of both Ex -situ and In-situ conservation during last two decades under the Odisha Millet Mission Project ,which is funded by Govt. of Odisha. The Collection of Germplasm with Conservation by conducting Field trials was consider as base line for present work in where assessment of diversity conserved in Millets and decide on future thrust area's for conservation. Augmentation and Conservation priorities were identified based on -

A) Phyto - geographical zones of Germplasm augmentation (Vis -a-Vis) prevalence of diversity.

B) Desirable trait's for Utilization and their significance for conservation on diversity.
C) Assessment of trait specific materials which are conserved for specific agro climatic conditions.

\section{Results and Discussion}

The collection, documentation, and conducting field trials ( Ex -situ conservation ) was started in two years ( Kharif 2019 ,Kharif 2020) with supported by Odisha Millet Mission Project by a network association with farmers in where indigenous seeds is operated in two site specific agro ecological zones :

3.1 - Germplasm Augmented in Millet's: - The Millets which are of both minor \& major millets constitute the total percentage of Germplasm collections-111no. During 2017 -2020 Germplasm diversity was assembled of native and rare Germplasm collected from different parts of Odisha, AP, and Chhattisgarh.

A total of 111no.of Millet Germplasm consisting of -Minor Millets - 106 no. ( Teff ( Eragrostis tef) -2 no , Brown top Millet (Brachiaria ramosa) -4no ,Kodo Millet ( Paspalum scrobiculatum) -2no ,Finger Millet ( Eleusine coracana )-66no. , Barnyard Millet ( Echinochola esculenta )-6no, Foxtail Millet ( Setaria italica )- 10no , Little Millet ( Panicum sumatrance ) - 16 no. ) Major Millets - 5 no.( Sorghum ( Sorghum bicolor)-4 no , Pearl Millet ( Pennisetum glaucum )-1 no) have been collected by Odisha Millet Mission ,Wassan ( Watershed Support Service \& Activities Network ) is a civic society playing lead role in implementing of Odisha Millet Mission Project (Table 1, and Figure 1).

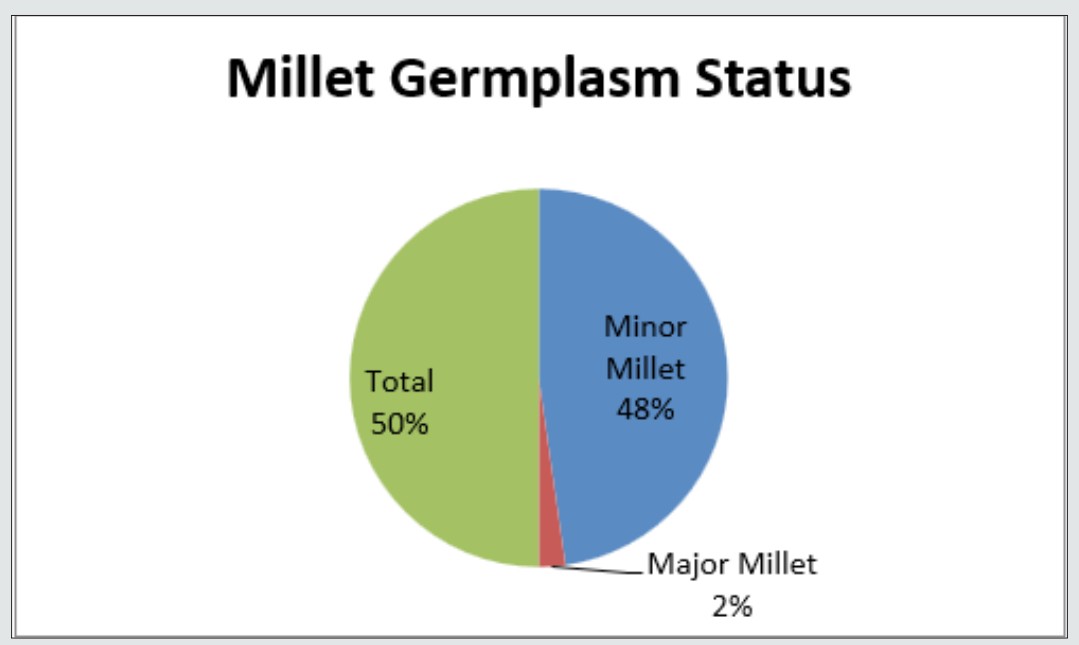

Figure 1:

Table 1: The Major Millets area coverage status during Kharif 2020 -21 in the prominent districts of Odisha.

\begin{tabular}{|c|c|c|c|}
\hline District name & Major Millet crop -Sorghum Area (Ha) & Major Millet crop- Pearl Millet Area (Ha) & No.of Potential blocks \\
\hline Koraput & 300 & 60 & 5 \\
\hline Gajapati & 400 & 100 & 2 \\
\hline Kandhamal & 50 & 30 & 3 \\
\hline
\end{tabular}

*** Data Source -District Agriculture Office, OMM Project 2020-21. 
Diversity Assembled under collaborative collection mission

Collaborative explorations were undertaken in different tribal parts of Odisha where the extensive work has coordinated with
Odisha Millet Mission .The Variability of Millet Germplasm's in between major and minor millet groups actively engaged by the project in where significant diversity in trait specific Germplasm was assembled for all millets several workshops on Germplasm conservation was undertaken in the project are given in Table -2 .

Table 2: The Exploration initiatives.

\begin{tabular}{|c|c|c|c|}
\hline Year & $\begin{array}{l}\text { Collaborative } \\
\text { institute }\end{array}$ & Crops \& no's & Collection Area \\
\hline $2017-18$ & Wassan ,OMM & $\begin{array}{l}\text { Finger millet -20 no. } \\
\text { Little Millet - 1no. }\end{array}$ & Nuapada ,Kalahandi district of Odisha \\
\hline $2018-19$ & Wassan ,OMM & $\begin{array}{l}\text { Finger millet -33 no. } \\
\text { Little Millet - 10no. } \\
\text { Sorghum - 4no. } \\
\text { Brown top Millet - 4no. } \\
\text { Kodo Millet - 2no. } \\
\text { Barnyard Millet - 4no. } \\
\text { Foxtail Millet - 5no. }\end{array}$ & $\begin{array}{c}\text { Koraput, Gajapati, Nuapada district of } \\
\text { Odisha and Bastra district of Chhattis- } \\
\text { garh. }\end{array}$ \\
\hline $2019-20$ & Wassan ,OMM & $\begin{array}{l}\text { Teff - 2no. } \\
\text { Barnyard Millet - 2no. } \\
\text { Little Millet - 3no. } \\
\text { Finger Millet - 10no. } \\
\text { Pearl Millet - 1no. } \\
\text { Foxtail Millet - 3no. }\end{array}$ & $\begin{array}{l}\text { Koraput, Gajapati district of Odisha and } \\
\text { Araku valley of Andhra Pradesh. }\end{array}$ \\
\hline $2020-21$ & Wassan ,OMM & $\begin{array}{l}\text { Finger Millet -3no. } \\
\text { Foxtail Millet - 2no. }\end{array}$ & Koraput district of Odisha. \\
\hline
\end{tabular}

\section{Germplasm introduction in Millets: - (Minor Millet Group)}

\section{Finger Millet (Eleusine coracana-L)}

A total of 66 no.of local landraces have been collected and introduced in Distinctness, Uniformity \& Stability (DUS) trial in different agro ecological zones of Odisha .Since 2019 to 2020 the trial was conducted in Koraput district of Odisha .the objective of the trial was to conserve the landraces and mapping important trait specific characters.

Findings - Obtaining Purified cultures from segregating generations.

\section{Little Millet (Panicum sumatrance -L):}

A total 16no.of local landraces have been collected and introduced in Distinctness, Uniformity \& Stability (DUS) trial in different agro ecological zones of Odisha .Since 2019 to 2020 the trial was conducted in Koraput district of Odisha the objective of the trial was to conserve the landraces and mapping important trait specific characters.

Findings -Obtaining Purified cultures from segregating generations.

\section{Foxtail Millet (Setaria italica)}

A total of 10no.of local landraces have been collected and introduced in Distinctness, Uniformity \& Stability (DUS) trial in different agro ecological zones of Odisha the objective of the trial was to conserve the landraces and mapping important trait specific characters.

Findings - Obtaining Purified cultures from segregating generations. 


\section{Kodo Millet (Paspalum scrobiculatum)}

A total of 2no.of local landraces have been collected and introduced in Distinctness, Uniformity \& Stability (DUS) trial in different agro ecological zones of Odisha the objective of the trial was to conserve the landraces and mapping important trait specific characters.

Findings - Obtaining Purified cultures from segregating generations and landraces are increased in their base material quantity.

\section{Teff (Eragrostis tef)}

A total of 2no.of local landraces have been collected and introduced in Distinctness, Uniformity \& Stability (DUS) trial in different agro ecological zones of Odisha the objective of the trial was to conserve the landraces and mapping important trait specific characters like non lodging ,high tolerant to drought

Findings - Obtaining Purified cultures from segregating generations and landraces are increased in their base material quantity.

\section{Brown top Millet (Brachiaria ramosa)}

A total of 4 no.of local landraces have been collected and introduced in Distinctness, Uniformity \& Stability (DUS) trial in different agro ecological zones of Odisha the objective of the trial was to conserve the landraces and mapping important trait specific characters like non lodging ,high tolerant to drought ,less grain shattering.

Findings - Obtaining Purified cultures from segregating generations and landraces are increased in their base material quantity.

\section{Barnyard Millet (Echinochola esculenta)}

A total of 6 no.of local landraces have been collected and introduced in Distinctness, Uniformity \& Stability (DUS) trial in different agro ecological zones of Odisha the objective of the trial was to conserve the landraces and mapping important trait specific characters like non lodging, resistance to shoot borer ,and neck blast.

Findings - Obtaining Purified cultures from segregating generations.

\section{(Major Millet group)- Sorghum (Sorghum bicolor):}

A total of 4 no.of local landraces have been collected and introduced in Distinctness, Uniformity \& Stability (DUS) trial in different agro ecological zones of Odisha the objective of the trial was to conserve the landraces and mapping important trait specific characters like non lodging, early maturity ,less grain shattering.

Findings - Obtaining Purified cultures from segregating generations.

\section{Pearl Millet ( Pennisetum glaucum )}

A total of 1 no.of local landraces have been collected and introduced in Distinctness, Uniformity \& Stability (DUS) trial in different agro ecological zones of Odisha .the objective of the trial was to conserve the landraces and mapping important trait specific characters like dwarf plant type, early maturity, resistant to smut .

Findings - Obtaining Purified cultures from segregating generations.

Presently the Project (Odisha Millet Mission) holds a total of 50 no.of Finger Millet indigenous accessions are maintained as in cryogenic preservation in State Seed Testing laboratory (SSTL) which will be use in further genomic studies of Finger Millet in crop improvement programme.

\section{Germplasm registration and utilization}

India has a very strong crop improvement programme by different research organisation, ICAR .during the process of Germplasm manipulations to meet the breeding requirements superior Genotypes are select to meet multiple trait specific characters from the Germplasm pools. And these multi trait specific Genotypes are to be released as state or central seed certification board for a certain geographical area. The Germplasm with one or more outstanding traits, which doesn't qualify to get notified because of poor agronomic performances are considered for registration which is an instrument of soft protection.

\section{Conclusion and Future Thrusts}

In the wake of international legalization with respect to Global plan of Action (GIA) networking has been included as a significant component of PGR management. Genetic erosion of local cultivars or landraces of many coarse cereals and particularly minor millets are evident in most crop growing areas.

The value of these under -exploited and under -utilized genetic resources needs to understand because of their excellent adoptability in stress prone environments. The situation warrants recognition of the importance of millets, especially small millets sown in hills and semi -arid regions .while collections , assembled in Germplasm of Wassan ,under Odisha Millet Mission project represent a small area of cultivation in which there are still rich in diversity pockets that needs to attention for exploration and collection .Keeping in views the importance of these regions ( Eastern ghat High lands) of Odisha for this kind of work on the one hand and fast rate of erosion in same and growing demands for crop improvement in others, there is a need to conserve the trait specific diversity and as well as local Genetic diversity .

\section{References}

1. (2006) ICAR Handbook of Agriculture, Indian Council of Agriculture Research, New Delhi: 892-912

2. Seetharam A ,Riley kw , Harinarayana G (1989) small millets in global agriculture. Proc First International Small millets workshop Bangalore ,India ,Octo29-November 2,1989 ,Oxford IBH Publishing Co.Pvt.Ltd ,New Delhi

3. (1991) Arora Rk Plant diversity in Indian Gene center. In (Eds. Rs Panda \& Rk Arora) Plant Genetic resources - conservation \& management. International Board for Plant Genetic Resources ,Regional office for South Asia \& South East Asia, NBPGR campus ,New Delhi: 25.54 
4. (1975 -2006) Annual Report National Bureau of Plant Genetic Resources (ICAR),Pusa campus ,New Delhi 110012
5. (1975-2006) Plant Germplasm Reporter, Compiled by Germplasm Exchange Division ,National Bureau of Plant Genetic Resources (ICAR) ,Pusa campus ,New Delhi.

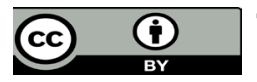

This work is licensed under Creative Commons Attribution 4.0 License

To Submit Your Article Click Here: Submit Article

DOI: $10.32474 /$ CIACR.2021.09.000318

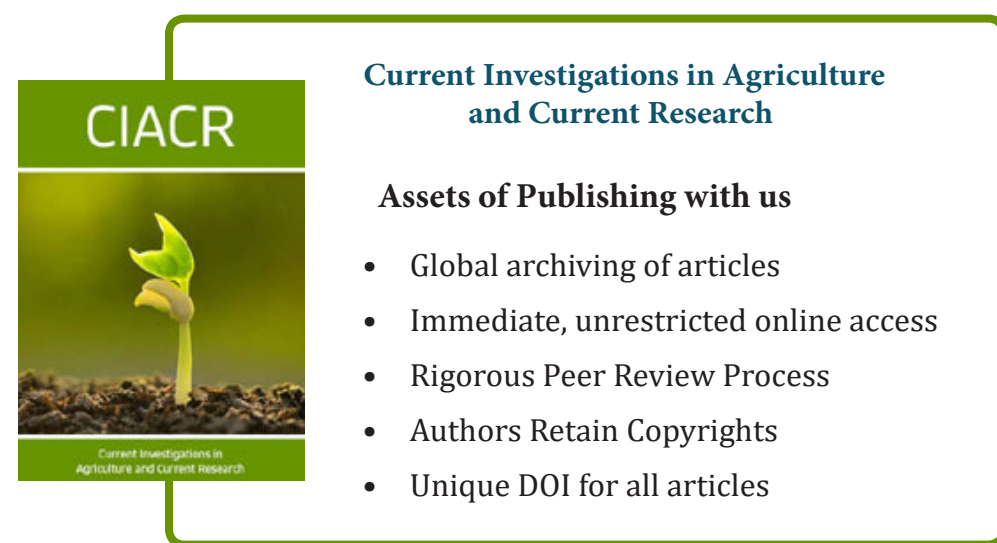

